than precludes, ${ }^{\prime}$ a fully integrated approach to the management of risk factors in a group of high risk patients. We would seek to justify the value of personal health education for these patients in terms of improvements in their reported diet, activity, freedom from symptoms, and quality of life.

M E CUPPLES Senior lecturer

A MCKNIGHT

Department of General Practice,

Queen's University of Belfast,

Dunluce Health Centre

Belfast BT9 7HR

1 Wierzbicki AS, Reynolds TM. Health promotion in general practice. BMf 1995;310:532-3. (25 February)

Cupples ME, McKnight A. Randomized controlled trial of health promotion in general practice for patients at high cardiovascular risk. BMf 1994;309:993-6. (15 October.)

\section{Criteria for authorship}

\section{Acceptance of a paper should not depend on where the researchers work}

EDITOR,-We agree with the criteria for authorship set out by the International Committee of Medical Journals Editors but wish to comment on the opposite case-that is, the criteria for exclusion from authorship, a topic that occupies part of the policies of some journals. In principle, these criteria should be the contrary of those mentioned by Goodman and should be related to the lack of scientific contribution of the author. ${ }^{1}$ This, however, is not always the case. For example, a recent editorial in the New England fournal of Medicine stated that analyses of cost effectiveness would not be considered for publication if one of the authors had a personal financial conflict of interests (that is, he or she was an employee of the company that made the product under study).$^{2}$ The editor's main justification for this policy is that studies of cost effectiveness are partly review articles based on data chosen selectively from the literature and that the choices could be biased.

It is true that analyses of cost effectiveness are particularly liable to bias. Bias may, however, operate in different directions. A potential source of bias could be for a payer to reduce its total health expenditure budget. Would it not be possible for a so called "neutral source," such as a government agency, to have an interest in showing that the cheapest drug is the most cost effective-particularly so when these institutions are the ones financing medicines, as in many European countries?

The question here is this. If a researcher working in, for example, the pharmaceutical industry has contributed to the elaboration of a pharmacoeconomic analysis, together with other researchers of a university or hospital, what is the "correct" attitude: to exclude his or her name from among the list of authors, refusing the right to authorship? Or not to publish the study, so increasing publication bias? Probably the researcher would choose the exclusion of his or her name so that the article was published.

We believe that for review articles it would be preferable to encourage the use of scientific selection criteria, such as meta-analysis, ${ }^{3}$ or to establish methodological guidelines for economic assessment, as exist for clinical trials or statistical analyses. The quality of any article must be judged a posteriori, after the necessary methodological requirements to prevent bias have been established. In that sense, the recent series articles on methodology for reviews may be useful in tackling the problem of bias analyses of cost effectiveness. ${ }^{4}$

We are in favour of basing the acceptance or rejection of a manuscript on the quality of the research and not on where the researchers work.

Basing it on where the researchers work constitutes a scientific prejudgment.

A SARCRISTAN Clinical pharmacologis JESUS M HERNANDEZ Director

Clinicaly,

Lilly,

Madrid,

Spain

1 Goodman NW. Survey of fulfilment of criteria for authorship in published medical research. BMf 1994;309:1482. (2 December.)

2 Kassirer JP, Angell M. The journal's policy on cost-effectiveness analysis. $N$ Engl f Med 1994;331:669-70.

3 Simes RJ, Glasziou PP. Meta-analysis and quality of evidence in the economic evaluation of drug trials. PharmacoEconomics 1992;1:282-92.

4 Oxman AD. Checklists for review articles. BMf 1994;309: 648-51.

\section{Statisticians should be coauthors}

EDIToR,-Neville W Goodman outlines criteria for authorship of published material. ${ }^{1}$ Medical research is often, by its nature, multidisciplinary, and frequently the authorship of papers reflects this. As statisticians we find that analysis is rarely just a "simple manipulation on a computer" but involves a great deal of time and care from the study's design stage, through checking of the data and statistical analysis, to presentation of the results. The application of "standard statistical tests" does not necessarily imply that the analysis was straightforward; it may imply that more complicated methods of analysis, which are often less easy to interpret, were considered to be inappropriate.

We therefore believe that statisticians' contribution to medical research should generally be recognised through coauthorship and not simply through their receiving "credit for what they have done and nothing more." Our criterion for a substantial contribution worthy of coauthorship is: processing the results; providing new insight into the data; or making a contribution without which the paper could not be published. These apply whether or not the statistician has been involved at the design stage. None of these, however, would be deemed as meriting coauthorship acording to Goodman's criteria.

Mere acknowledgement of a statistician does not guarantee that appropriate statistical analysis has been done or its interpetation published. It is important that the statistician coauthors the paper, and implicit in this is that he or she approves the final version. The recommendation in Goodman's paper undervalues statisticians' contribution to medical research and if generally applied could act as a deterrent to statisticians' collaboration. MARK A MULLEE FIONA C LAMPE Senior statistical programme Statistician STEVEN a JULIOUS Lecturer in medical statistics Statistician

Medical Statistics and Computing

University of Southampton,

Southampton General Hospital,

Southampton SO16 6YD

1 Goodman NW. Survey of fulfilment of criteria for authorship in published medical research. BMF 1994;309:1482. (3 December.)

\section{Continuing medical education and gift authorship}

Editor,-The Royal College of Pathologists recently published details of the system that it will adopt for awarding points for continuing medical education. ${ }^{1}$ A minimum of 250 points will have to be acquired over five years. The points can be earned through a variety of activities, including authorship of refereed articles in journals: 10 points for the first author, five for the second, and one for other authors. I have not examined the details of schemes run by the other royal colleges but suspect that they are similar. My reservations about the wisdom of awarding different numbers of points according to the order of authorship were reinforced and extended by the report of gift authorship at St George's Hospital Medical School. ${ }^{2}$ The survey by Neville W Goodman ${ }^{3}$ and the editorial by Jane Smith ${ }^{4}$ present a challenge to editors and authors alike.

Authorship of a scientific or medical paper should be for the few who make a substantial contribution; acknowledgment should be for the many valuable, even essential, supporters. If we fail to correct the practice, endemic in the scientific and medical world, of authorship by association or seniority we deserve the contempt of colleagues and will have to accept that the laudable system of continuing medical education will penalise the honest and reward the unscrupulous.

STEPHEN P HALLORAN Editor in chief, Annals of Clinical Biochemistry Department of Clinical Biochemistry,

Immunology, and Nutrition,

Royal Surrey County and St Luke's Hospital,

Guildford,

Surrey GU1 3NT

1 Flynn FV. Continuing medical education. Association of Clinical Biochemists News Sheet 1994;376:118-23.

2 Court C, Dillner L. Obstetrician suspended after research inquiry. $B M F$ 1994;309:1459. (3 December.)

Goodman NW. Survey of fulfilment of criteria for authorship in published medical research. BMf 1994;309:1482. (3 December.)

4 Smith J. Gift authorship: a poisoned chalice? BMF 1994;309: 1456-7. (3 December.)

**Dr Halloran's reservations about points being awarded on the basis of the order of authorship are well founded. Conventions over order differ between departments, specialties, and countries. When the Vancouver group (the International Committee of Medical Journal Editors) investigated the issue in order to produce some sensible guidance all it could conclude was: "Because order of authorship is assigned in different ways, its meaning cannot be inferred accurately unless it is stated by the authors."-EDITOR, $B M \mathcal{F}$

\section{Royal College of Pathologists' reply}

EDITOR,-During the past year the Royal College of Pathologists has been conducting trials of its continuing medical education scheme ${ }^{1}$ in the Wessex and South East Thames regions as a prelude to introducing continuing medical education for all doctors holding relevant career grade posts in pathology in Britain by April. Minor modifications to the scheme are currently being made to take account of comments by members on the original proposals and the feedback received from participants in the trials. Among the changes to be introduced is one that addresses the reservations expressed by $S \mathrm{P}$ Halloran about the method of allocating credits for continuing medical education among authors of refereed papers. Many other members have expressed disquiet about different numbers of credits being awarded for this self learning activity according to the order of the authors' names, but opinions on what would be acceptable have varied. Recently it was decided that, to satisfy the majority of critics, from April a fixed number of credits will be shared equally among all the authors, the number allocated to each being rounded up to the nearest whole number when necessary.

In preparation for the British launch of the college's scheme other adjustments are being made with the object of achieving harmonisation with the other medical royal colleges' plans for continuing medical education; this policy is being pursued by a committee of directors of continuing medical education formed under the aegis of the conference of colleges. Other changes will 